\title{
Contribuições locais para consecução dos objetivos da Agenda de 2030:experiências de uma Universidade Comunitária
}

\section{Local Contributions towards achieving the 2030 Agenda Goals: experiences from a Community College}

DOI: $10.54018 /$ sssrv2n2-005

\author{
Miguelangelo Gianezini \\ Doutor em Agronegócios \\ UNESC - Universidade do Extremo Sul Catarinense \\ Avenida Universitária 1105, Universitário, Criciúma-SC, Cep. 88.806-000, Fone \\ 48 3431-2500 \\ E-mail: miguelangelo@unesc.net
}

\section{Zanoni dos Santos Elias}

Mestre em Contabilidade

UNESC - Universidade do Extremo Sul Catarinense

Avenida Universitária 1105, Universitário, Criciúma-SC, Cep. 88.806-000, Fone 48 3431-2500

E-mail: zanonielias@gmail.com

\section{RESUMO}

A Agenda 2030 é um ambicioso plano de ação que conta com 17 Objetivos de Desenvolvimento Sustentável e 169 metas para construção de uma sociedade melhor. Muitos são os agentes e organizações que podem contribuir para a consecução de tais objetivos, sendo as Universidades, as que apresentam grande potencial para tal. No presente estudo, se buscou identificar as experiências de uma Instituição Comunitária de Ensino Superior (ICES) do Sul do Brasil, investigando com quais ODS contribuem, quais são suas influencias para 0 alcance da Agenda 2030 e por intermédio de que projetos atuam. Para isso, foi conduzido estudo documental com coleta no mês de maio de 2021, em documentos e relatórios da própria instituição, comparando-os com a Agenda. Como resultado, contabilizou-se mais de cem programas e projetos sociais, ambientais e culturais. Foi possível identificar todos os 17 ODS representados por meio dos mesmos. O programa com maior influência na comunidade foi o de Clínicas Integradas da Saúde. O estudo corrobora com a proposta das ICES, que por sua natureza comunitária têm maior propensão a impactar em localidades nas quais que estão inseridas.

Palavras-chave: ODS, Educação Superior, Público não-estatal, Brasil. 


\section{ABSTRACT}

The 2030 Agenda is an ambitious plan of action that includes 17 Sustainable Development Goals and 169 targets for building a better society. Many are the agents and organizations that can contribute to the achievement of such goals, and universities have great potential for this. In this study, we sought to identify the experiences of a Community Institution of Higher Education (ICES) in southern Brazil, investigating which SDGs they contribute to, what are their influences on the achievement of the 2030 Agenda, and through which projects they work. To this end, a documental study was conducted with data collected in May 2021 from documents and reports of the institution itself, comparing them with the Agenda. As a result, more than one hundred social, environmental, and cultural programs and projects were identified. It was possible to identify all the 17 SDGs represented through them. The program with the greatest influence on the community was the Integrated Health Clinics program. The study corroborates the proposal of the HEls, which by their community nature have a greater propensity to impact on localities in which they are inserted.

Keywords: SDGs, Higher Education, Non-State Public, Brazil.

\section{INTRODUÇÃO}

A Agenda 2030 estabelece um importante plano de ação para a construção de uma sociedade melhor, sendo assinada por 193 países no ano de 2015. Visando a transformação do mundo através do desenvolvimento sustentável e a busca por dignidade de vida, tanto nas dimensões econômicas, quanto sociais e ambientais, o projeto delimita 17 Objetivos de Desenvolvimento Sustentável e 169 metas que servem como orientação para consolidar essa mudança planetária. Esses objetivos são colocados em prática tanto como responsabilidade dos governos, como setores privados, comunitários e da própria sociedade civil.

Dentro deste contexto, as Instituições Comunitárias de Ensino Superior (ICES), surgem como um importante agente social. Estas, são organizações não estatais e sem fins lucrativos, fundamentas na construção do ensino, pesquisa e extensão, que atuam na comunidade local onde estão inseridas. No Brasil são regulamentadas pela Lei 12.881/2014.

De maneira geral, pode-se afirma que as ICES contribuem diretamente com a comunidade em que estão inseridas, já que seu compromisso como universidades comunitárias são o desenvolvimento regional, principalmente auxiliando pessoas menos favorecidas no âmbito social e econômico, além daquelas que se encontram em situação de vulnerabilidade.

Por isso, esse breve trabalho busca analisar as experiências de uma 
Universidade Comunitária localizada no Sul do Brasil com foco em ações relacionadas aos Objetivos de Desenvolvimento Sustentável (ODS) estabelecidos conforme a Agenda 2030. Serão elencados quais dos 17 ODS estão presentes direta ou indiretamente nas atividades da organização, além investigar quais são os programas, projetos e/ou ações que existem atualmente na instituição, elucidar a importância para a comunidade local e por fim, avaliar possíveis pontos negativos e como melhorar os mesmos, caso forem identificados.

Esse estudo ressalta a importância de Instituições Comunitárias de Ensino Superior, o seu valor socioeconômico, além de trazer bons exemplos de projetos e programas sociais que façam a conexão da comunidade com o ambiente acadêmico e que visem os avanços da sociedade como um todo, caminhando em direção aos Objetivos de Desenvolvimento Sustentável.

\section{MÉTODO}

A universidade foco deste estudo está localizada no Sul do estado de Santa Catarina. De acordo com a Lei 12.881/2013, a referida Universidade se caracteriza como uma Instituição Comunitária de Ensino Superior, isto é, não possui fins lucrativos e está fundamentada nos pilares ensino, pesquisa e extensão.

A coleta de dados para análise foi feita no mês de maio de 2021, a partir de documentos e relatórios disponibilizados pela própria universidade, disponíveis em seu website. A corelação feita com o documento oficial da Agenda 2030 para o Desenvolvimento Sustentável, levando em consideração todos os Objetivos de Desenvolvimento Sustentável.

\section{RESULTADOS E DISCUSSÃO}

De acordo com os documentos disponibilizados pela própria instituição, foram contabilizados mais de cem programas e projetos, incluindo atividades de extensão, programas gratuitos oferecidos e atividades institucionais. A maioria dos programas estão no âmbito social, ambiental e cultural. Levando em consideração os dados oferecidos no Plano de Desenvolvimento Institucional (PDI) de 2020, foram mais de 150 mil beneficiados com os serviços oferecidos pela universidade. Além disso, a universidade conta também com bolsas de 
estudos que não foram levadas em consideração nos números apresentados, mas que são importantes para a comunidade.

Na tabela (1) observa-se os dez programas/projetos com maior influência, também de acordo com o PDI.

Tabela 1- Relação dos dez programas e projetos com maior destaque em relação ao número de beneficiados.

\section{PROGRAMA/PROJETO}

Clínicas Integradas da Saúde

Cidadanina Verde: plano do Sistema de Espaços Livres no município de Morro da Fumaça, na perspectiva da paisagem local e microrregional e da cidade educadora"

\begin{tabular}{|c|c|}
\hline Comissão de Meio Ambiente e Valores Humanos & 6.236 \\
\hline Centro Especializado de Reabilitação - CER & 5.872 \\
\hline $\begin{array}{l}\text { Escolas de pais e filhos: diálogos entre Universidade, Escolas e } \\
\text { Comunidade }\end{array}$ & 5.643 \\
\hline Farmácia Solidária & 4.900 \\
\hline $\begin{array}{l}\text { Observarório Acessível - Subsídios das tecnologias assistivas para } \\
\text { adequação e qualificação de acessibilidade espacial em escolas do } \\
\text { município de Morro da Fumaça em parceira com o Observatório Social }\end{array}$ & 2.257 \\
\hline Recuperação de Área Degradada (PRAD) do lixão & 2.245 \\
\hline $\begin{array}{l}\text { Complexo Educacional Bairro da Juventude - Criciúma/SC: Revitalização } \\
\text { e adequação dos espaços físicos comunitários ao Projeto Pedagógico da } \\
\text { instituição }\end{array}$ & 1.794 \\
\hline Casas da Cidadania & 1.391 \\
\hline TOTAL & 127.130 \\
\hline
\end{tabular}

Do autor, 2021
№ BENEFICIADOS

80.666

16.126

6.236

127.130

Proporcionalmente ao número de beneficiados, visto na tabela anterior, o ODS que mais teve representatividade foi Saúde e Bem-estar (3), seguido de Educação de Qualidade (4) e Redução das Desigualdades (10). Dentre os 17 Objetivos de Desenvolvimento Sustentável estabelecidos na Agenda 2030, todos foram citados nos relatórios, sem exceção. Fato que demonstra a preocupação da instituição em colaborar com as metas propostas pelo plano da Agenda.

Instituições comunitárias tornam-se essenciais para construção uma realidade melhor, contribuindo diretamente para 0 desenvolvimento socioeconômico da região em que estão inseridas e consequentemente para a sociedade como um todo.

A participação das organizações privadas e não estatais para o alcance dos ODS são de grande relevância, já que evitam sobrecarregar as demandas apenas pros órgãos públicos e conseguem agir com foco maior nos municípios e microrregiões. Conseguem assim, interagir em parceria com a população e com os governos, fortalecendo os propósitos da Agenda 2030. 


\section{CONCLUSÕES}

Nesta seção de considerações finais reitera-se que foi possível identificar todos os 17 ODS representados, sendo que o programa com maior influência na comunidade foi o de Clínicas Integradas da Saúde. O estudo corrobora assim com a proposta das ICES, que por sua natureza comunitária têm maior propensão a impactar em localidades nas quais que estão inseridas. A Universidade em questão, pelo seu perfil comunitário, oferece diversos programas e projetos sociais, ambientais e culturais, além de bolsas de estudos e outros serviços prestados ao público interno e externo da instituição, gerando inúmeros resultados positivos e beneficiando não só a população, como o meio ambiente.

Os 17 ODS, portanto, são representados de alguma maneira na atuação da instituição, como apresentado no Plano de Desenvolvimento Institucional, demonstrando a preocupação em relação a Agenda 2030, não sendo observados pontos negativos significativos. 


\section{REFERÊNCIAS}

Lei n. 12.881, de 12 de novembro de 2013 (2013). Dispõe sobre a definição, qualificação, prerrogativas e finalidades das Instituições Comunitárias de Educação Superior - ICES, disciplina o Termo de Parceria e dá outras providências. Brasília, DF. Recuperado de https://www2.camara.leg.br/legin/fed/lei/2013/lei-12881-12-novembro-2013777421-publicacaooriginal-141829-pl.html

Relatório Balanço Social (2019). Responsabilidade Social. Criciúma, SC. Recuperado de http://www.unesc.net/portal/resources/official_documents/18920.pdf?160098204 6

Schmidt, J. P. (Org.) (2009). Instituições Comunitárias: instituições públicas não-estatais. Santa Cruz do Sul, RS: EDUNISC. 